\section{Concentric conversations}

\author{
John Launer
}

Over the years, working in various roles, I have done quite a lot of work in the area of team facilitation and conflict resolution. Sometimes this has been with groups of doctors like general practitioners (GPs) who are not getting along with each other. These days, a lot of my work is with teams of hospital doctors who are having difficulty in balancing their clinical and training obligations. In all this work, I take an approach I describe as 'concentric conversations'. This draws on a range of ideas from the world of organizational work, particularly from the psychologist David Campbell who was one of my own teachers ${ }^{12}$ and from the work of Ralph Stacey, who looks at organizations in terms of the 'complex responsive processes' that happen there. ${ }^{3}$ The approach is based on a belief that change in organizations generally takes place not through mission statements, action plans and restructuring, but by encouraging more open and attentive conversations, from moment to moment and day to day. In this article, I want to describe how such an approach works, and what team facilitation looks like in practice.

Although every piece of organizational work is different, nearly all of them start in the same way-with an inquiry from an individual. Someone contacts a facilitator like myself with a concern about a team they belong to, or hold responsibility for. Often, this person starts off straight away with a request for a team 'awayday'. They may say something like the following (and this is scarcely an exaggeration): No-one in our team has spoken to each other for years, and we'd like you to come and meet us all for a day and make us all behave nicely'. Personally, I always decline. At best, an awayday in these circumstances will only get people to smile at each other and conceal the real problems. At worst, it will encourage everyone to haul skeletons out of every cupboard and start to hurl the bones at each other, without allowing time to nurse the resulting bruises. When a group of people have run into trouble, change takes time and it has to be brought about

Correspondence to: Dr John Launer, Faculty Development, Health Education England, Stewart House, 32 Russell, London WC1B 5DN, UK: john.launer@nwl.hee.nhs.uk gradually and with diplomacy. Awaydays may be a useful option once communication has started to open up properly, but this takes patience and great deal of preparation.

\section{MODELLING REFLECTION}

Like most people doing this kind of work, I have discovered that the best way to start any piece of team development is by having an extended conversation with the original inquirer. This involves asking questions like these: What is your concern? What is the nature of your own responsibility? Who else is involved? What are your relationships like with these people? Who is likely to be helpful? Who might feel upset or threatened by any action? This one-to-one dialogue is a vital part of any project, and the first of the 'concentric conversations' that I hope to hold over the next few days or weeks. The aim of this initial talk is not just to map out the difficulties. It is also to model the way I plan to continue, by slowing things down, applying analysis and reflection, and not jumping to instant diagnoses or magical solutions. The same applies to the every stage of the process. Working in the National Health Service (NHS) it is also essential to discover from the outset if there is any perceived risk of harm to patients, and who will need to be informed if that is the case. If the problem is one where other stakeholders have an interest, including senior management or regulators, their views need to be sought as well.

Frequently, the person expressing concern about a workplace problem can list many individuals who feel apathetic, upset or angry about it, but the most helpful way forward is to set up an initial meeting with one or two other people within the system who have some motivation, and hopefully enough goodwill, to try and change this state of affairs. To give an example, if the first person phoning me up is a senior educator in a hospital who has heard persistent complaints about junior staff being undermined on a unit, I will aim to meet next with the educator and a couple of consultants who do not appear to be implicated in the complaints, but who know about these and want to address them. Stage two of 'concentric conversations' is to get this small group of people together in a room, find out their views about the problem, and look at possible ways forward. This depends on taking the same stance as before: accepting that the problem is significant and possibly serious, but without making hasty judgements, and by promoting dialogue. Interestingly, people are often familiar with this painstaking kind of fact-finding exercise in their clinical work, but find it surprising that the same precise and unprejudiced inquiry might work in the area of human relationships as well. They may be less familiar with the idea that this style of inquiry can itself free up a discussion of difficult topics and reduce strong emotion-and well as emboldening them to start having some of the challenging conversations that they have avoided.

\section{LARGE GROUP}

At some point in any team facilitation project, there is usually a need to bring a large group of people together. This may be a whole GP practice or primary care team, a group of hospital consultants, a cohort of trainees, or even the consultants and trainees on a unit together. By the time this occurs, I always hope to have built trusting relationships with several individuals who will be there. They will then be able to reassure their colleagues the occasion will not be explosive, and can attend with optimism rather than too much apprehension. Like most other facilitators in this field, I always conduct these large meetings together with a colleague with similar experience and skills. Working with another person helps you to stay calm if things get heated. The two of you can take it in turns to conduct the meeting or to observe it in silence. If necessary, you can even take a break together to discuss the best way forward. There is helpful literature on how groups in conflict can unsettle or disable anyone who tries to help them, by a kind of parallel process ${ }^{4}$. It is important for facilitators to be able to hold on to a position of neutrality and resolute courtesy even at moments when others in the room are not. If you can do so, you can help large groups understand how it is possible to resolve differences, or at least to find a compromise that allows them to tolerate these without disrespect. Sometimes it takes more than a single large group meeting to achieve this.

The final stage of 'concentric conversations' has to involve closure. Just as with individual or group therapy, there is little point in helping people to air and address their difficulties, unless they can gain the confidence to continue doing so by 
themselves. This is one of the reasons why offering a quick fix like an awayday is less effective than demonstrating how frank but respectful conversations can take place within teams without the sky falling in. Realism plays a part here too, especially when it turns out that someone within the system has been genuinely obstructive or irremediably disaffected, or is genuinely incapable of fulfilling a role. In such instances, change may only be possible with the robust intervention of management. However, people who have been perceived by their colleagues as the most difficult at the outset often turn out to be surprisingly capable of transforming their attitudes and behaviour. They may even be happy to step aside for others. You can never exactly predict where 'concentric conversations' will lead, but if you trust the process, you almost always find this is a better place than the one where you started.

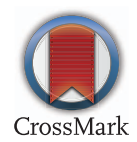

To cite Launer J. Postgrad Med J 2015;91:177-178.

Postgrad Med J 2015:91:177-178.

doi:10.1136/postgradmedj-2015-133293

\section{REFERENCES}

1 Campbell D. Connecting personal experience to the primary task: a model for consulting to organizations. In: Cooklin A., ed. Changing organizations: clinicians as agents of change. London, Karnac, 1999:43-62.

2 Campbell D, Huffington C, eds. Organizations connected: a handbook of systemic consultation. London, Karnac, 2008.

3 Stacey R. Complex Responsive Processes in Organizations: Learning and Knowledge Creation. London, Routledge 2001.

4 Obholzer A, Zagier Roberts V, eds. The Unconscious at Work: Individual and Organizational Stress in the Human Services. London, Routledge, 1994. 